\title{
Methods for Reducing the Stress Concentration in Cylindrical Specimens, at Axial Loading
}

\author{
Raycho Raychev \\ Faculty of Mechanical Engineering \\ Technical University of Sofia, Branch Plovdiv \\ Plovdiv, Bulgaria \\ rpraichev@tu-plovdiv.bg
}

\author{
Ivanka Delova \\ Faculty of Mechanical Engineering \\ Technical University of Sofia, Branch Plovdiv \\ Plovdiv, Bulgaria \\ prosto_vanq89@abv.bg
}

\begin{abstract}
The article presents specialized software methods for reducing stress concentration. Objects of study are cylindrical test specimens subjected to axial loading. Notching with different shapes and sizes on the specimens were formed to reduce the stresses in the endangered areas. The geometric parameters of notches identified through the specialized built-in modules to the ANSYS software. An analysis performed were to show the influence of stresses acting on the fatigue limit during different cycles. The results of the study were present in a graphical form.
\end{abstract} notch.

Keywords - stress concentration, ANSYS, axial loading,

\section{INTRODUCTION}

Stress concentrations are one of the main problems that arise in the construction of parts in mechanical engineering. Increasing stresses in local areas can lead to loss of performance or destruction of components. This is one of the main reasons why the optimization of the details in mechanical engineering is related to the reduction of the stress concentration and the increase of the fatigue limit.

The reduction of stress concentration is the subject of a number of specialized literature sources.

An optimization approach for stress reduction in stepped specimens subjected to axial loads is proposed in [1]. The purpose of optimization is to minimize the maximum value of stresses in the main shoulder fillet, thus increasing the fatigue limit. The objects of study are two stepped details: the first with the presence of only a basic shoulder fillet, and the second with the presence of a basic shoulder fillet and an additional cylindrical notch. The main approach presented by the authors consists in defining geometric parameters to be optimized to achieve a minimum value of the objective function. Specialized software MATLAB and ANSYS were used for performing the optimization.

Elaboration of an additional cylindrical channel in the danger zones in order to reduce the stresses in a specific steel part is presented in [2]. The stress values are obtained by the finite element method using the specialized MARC/MENTAT software. The results show that due to the additional channel, the equivalent stresses decrease by about $10 \%$

Determining the best shape of shoulder fillet for stepped shafts and plates so that the maximum equivalent stress has the lowest possible value is a key goal in [3]. The optimization task is achieved with the help of a stochastic global search algorithm called "direct search simulated annealing". The optimized shape of the shoulder fillet is obtained with the help of spline curves passing through certain key points.

The analysis of the obtained results shows that the applied "direct search simulated annealing" method not only reduces the stress values, but also the optimized shoulder fillet are located on a smaller area.

A study of the stress concentration at a stepped shaft subjected to an axial load is described in [4]. Two types of shafts are considered: a stepped shaft with shoulder fillet of the foot and a shaft with shoulder fillet and a conical part of the foot. A simulation was realized with the help of the specialized ANSYS software. The analysis of the obtained results shows that:

- The coefficient of stress concentration at the step shaft is $30 \%$ higher than the coefficient known from the specialized literature.

- The stress concentration factor for a stepped shaft with a conical part is lower than that of a stepped shaft without a conical part by $5-10 \%$. 
An approach to stress reduction in stepped shafts is presented in [5]. It is based on the methods CAO (Computer Aided Optimization) and FEM, which are used to optimize the geometric parameters, with the main shoulder fillet located between the steps of the shafts. Different variants of optimized shoulder fillet are proposed, in which the stress concentration is significantly lower compared to the shoulder fillets before optimization.

The main goal of the present work is to reduce the stress concentration in cylindrical test specimens subjected to axial loading with the help of the specialized ANSYS software.

\section{MATERIALS AND METHODS}

Objects of study are a cylindrical part with a centrally located U-shaped notch and a two-stage cylindrical part with a shoulder fillet. Both specimens are subjected to axial loading.

Schemes of the examined specimens are presented in Fig. 1, and the values of their geometrical parameters are given in Table I and Table II.

The simulations are realized with the help of the static module to the specialized ANSYS software. Initially, the specimens are subjected to axial loading and the values of the maximum stresses at different geometric ratios of the input parameters are determined.
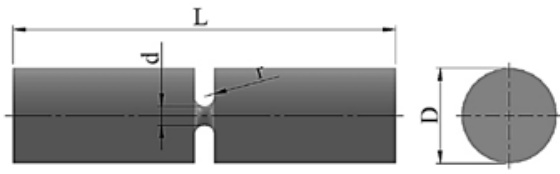

(a)
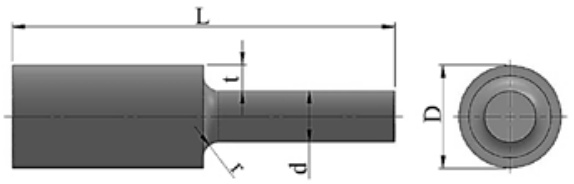

(b)

Fig. 1. Objects of study: (a) U-shaped specimen, (b) Specimen with shoulder fillet.

TABLE I.

\begin{tabular}{|c|c|c|c|}
\hline Geometric & nsions of $t$ & ecimen wit & -shaped no \\
\hline$D, m m$ & $r, m m$ & $L, m m$ & $d, m m$ \\
\hline & & & 5 \\
\hline & & & 15 \\
\hline 50 & 0,5 & 200 & 25 \\
\hline & & & 35 \\
\hline & & & 45 \\
\hline
\end{tabular}

TABLE II.

\begin{tabular}{|c|c|c|c|c|}
\hline \multicolumn{5}{|c|}{$\begin{array}{l}\text { Geometric dimensions of the specimen with the presence } 0 \\
\text { shoulder fillet. }\end{array}$} \\
\hline$D, m m$ & $d, m m$ & $L, m m$ & $t, m m$ & $r, m m$ \\
\hline \multirow{5}{*}{54} & \multirow{5}{*}{27} & \multirow{5}{*}{200} & \multirow{5}{*}{13.5} & 2,7 \\
\hline & & & & 4,05 \\
\hline & & & & 5,4 \\
\hline & & & & 6,75 \\
\hline & & & & 8,1 \\
\hline
\end{tabular}

The coefficients of stress concentration are determined with the obtained results from the simulation. These coefficients are compared with those existing in the specialized literature [6]. In order to reduce the stresses in the endangered areas, additional notches with specific shapes and sizes were made on the specimens. With the help of the built-in ANSYS module OptiSLang, the geometrical parameters of the additional notches were identified, and a target function was set to minimize the maximum values of the stresses in the endangered areas.

With the help of the specialized module ANSYS nCodeDesignLife the influence of the additional notches on the fatigue limit in the examined samples was reported.

The stress concentration coefficients for both specimens are determined according to (1):

$$
K_{t n}=\frac{\sigma_{\text {max }}}{\sigma_{\text {nom }}} ; \quad \sigma_{\text {nom }}=\frac{4 P}{\pi d^{2}}
$$

Where $P$ is the axial force applied to the specimen.

\section{RESULTS AND DISCUSSION}

Fig. 2 shows the specific geometric shapes of the additional notches used in the simulations of the cylindrical specimen with a central U-notch.

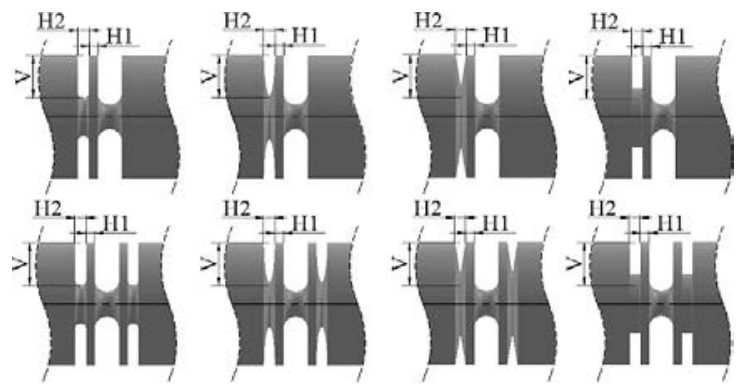

Fig. 2. Geometric shapes of the notches in the cylindrical specimen with a central U-notch.

Table III present the obtained values for the stresses and the concentration coefficient after the simulations, for different geometrical parameters $\mathrm{d}$.

Table IV presents the values of the geometric parameters of the additional notches obtained after the optimization with OptiSLang, the maximum stresses at these parameters, as well as the stress concentration coefficient.

TABLE III.

\begin{tabular}{|c|c|c|c|c|}
\hline \multicolumn{5}{|c|}{$\begin{array}{l}\text { Results from the simulation of a cylindrical specimen with } \\
\text { a U-shaped notch. }\end{array}$} \\
\hline Parameter & Axial force & $\sigma$ nom & $\sigma \max$ & Ktn \\
\hline $\mathrm{d}, \mathrm{mm}$ & $P, N$ & $M P a$ & $M P a$ & - \\
\hline 5 & \multirow{5}{*}{2000} & 101,859 & 272,34 & \begin{tabular}{|l|}
2,673 \\
\end{tabular} \\
\hline 15 & & 11,317 & 49,592 & \begin{tabular}{|l|}
4,381 \\
\end{tabular} \\
\hline 25 & & 4,0743 & 23,538 & 5,777 \\
\hline 35 & & 2,078 & 13,269 & 6,383 \\
\hline 45 & & 1,257 & 6,4164 & 5,102 \\
\hline
\end{tabular}


Environment. Technology. Resources. Rezekne, Latvia Proceedings of the $13^{\text {th }}$ International Scientific and Practical Conference. Volume 3, 300-303

TABLE IV.

\begin{tabular}{|c|c|c|c|c|c|}
\hline $\begin{array}{c}\text { Additional } \\
\text { notches }\end{array}$ & $\begin{array}{l}\text { H1, } \\
\text { mm }\end{array}$ & $\begin{array}{l}\text { H2, } \\
\text { mm }\end{array}$ & $\begin{array}{l}\text { V1, } \\
\text { mm }\end{array}$ & $\begin{array}{c}\sigma \text { max, } \\
\text { MPa }\end{array}$ & $\begin{array}{c}\text { Ktn } \\
-\end{array}$ \\
\hline \multicolumn{6}{|c|}{$d=5 \mathrm{~mm}$} \\
\hline U-notch & 2,459 & 1,250 & 21,013 & 192,987 & 1,895 \\
\hline V-notch & 1,622 & 2,222 & 20,988 & 237,063 & 2,327 \\
\hline Prismatic notch & 4,636 & 1,873 & 15,249 & 243,613 & 2,392 \\
\hline Elliptical notch & 2,471 & 1,471 & 18,485 & 200,065 & 1,964 \\
\hline $\begin{array}{l}\text { Double-sided U- } \\
\text { notch }\end{array}$ & 3,426 & 1,452 & 18,620 & 180,924 & 1,776 \\
\hline $\begin{array}{l}\text { Double-sided V- } \\
\text { notch }\end{array}$ & 2 & 2 & 15 & 241,069 & 2,367 \\
\hline $\begin{array}{l}\text { Double-sided } \\
\text { Prismatic notch }\end{array}$ & 0,859 & 0,851 & 16,312 & 242,990 & 2,386 \\
\hline $\begin{array}{l}\text { Double-sided } \\
\text { Elliptical notch }\end{array}$ & 4,018 & 4,305 & 19,591 & 205,433 & 2,017 \\
\hline \multicolumn{6}{|c|}{$d=15 \mathrm{~mm}$} \\
\hline U-notch & 2,579 & 1,694 & 14,878 & 39,795 & 3,516 \\
\hline V-notch & 3,274 & 2,087 & 11,087 & 46,535 & 4,112 \\
\hline Prismatic notch & 1,461 & 1,809 & 17,572 & 34,879 & 3,082 \\
\hline Elliptical notch & 3,870 & 0,731 & 9,972 & 39,113 & 3,456 \\
\hline $\begin{array}{l}\text { Double-sided U- } \\
\text { notch }\end{array}$ & 2,825 & 0,500 & 11,838 & 39,690 & 3,507 \\
\hline $\begin{array}{l}\text { Double-sided V- } \\
\text { notch }\end{array}$ & 2,015 & 1,983 & 15,085 & 38,002 & 3,358 \\
\hline $\begin{array}{l}\text { Double-sided } \\
\text { Prismatic notch }\end{array}$ & 1,526 & 2,292 & 10,553 & 41,946 & 3,706 \\
\hline $\begin{array}{l}\text { Double-sided } \\
\text { Elliptical notch } \\
\end{array}$ & 1,441 & 4,714 & 9,500 & 37,414 & 3,306 \\
\hline \multicolumn{6}{|c|}{$d=25 \mathrm{~mm}$} \\
\hline U-notch & 1,023 & 4,195 & 13,461 & 12,233 & 3,003 \\
\hline V-notch & 1,705 & 2,232 & 8,321 & 21,514 & 5,281 \\
\hline Prismatic notch & 2,484 & 1,844 & 12,381 & 15,069 & 3,699 \\
\hline Elliptical notch & 4,979 & 4,439 & 12,398 & 15,848 & 3,890 \\
\hline $\begin{array}{l}\text { Double-sided U- } \\
\text { notch }\end{array}$ & 1,070 & 4,998 & 12,982 & 9,801 & 2,406 \\
\hline $\begin{array}{l}\text { Double-sided V- } \\
\text { notch }\end{array}$ & 3,013 & 3,709 & 11,021 & 15,535 & 3,813 \\
\hline $\begin{array}{l}\text { Double-sided } \\
\text { Prismatic notch }\end{array}$ & 1,930 & 2,941 & 11,473 & 13,574 & 3,332 \\
\hline $\begin{array}{l}\text { Double-sided } \\
\text { Elliptical notch } \\
\end{array}$ & 3,241 & 4,059 & 3,545 & 16,128 & 3,959 \\
\hline \multicolumn{6}{|c|}{$d=35 \mathrm{~mm}$} \\
\hline U-notch & 3,521 & 3,726 & 8,514 & 7,360 & 3,540 \\
\hline V-notch & 3,770 & 2,858 & 6,402 & 10,968 & 5,276 \\
\hline Prismatic notch & 1,839 & 1,421 & 7,501 & 8,738 & 4,203 \\
\hline Elliptical notch & 2,930 & 2,720 & 5,945 & 9,674 & \begin{tabular}{|l|}
4,653 \\
\end{tabular} \\
\hline $\begin{array}{l}\text { Double-sided U- } \\
\text { notch }\end{array}$ & 3,848 & 5,000 & 7,781 & 5,314 & 2,556 \\
\hline $\begin{array}{l}\text { Double-sided V- } \\
\text { notch }\end{array}$ & 3,254 & 2,756 & 5,730 & 9,189 & 4,420 \\
\hline $\begin{array}{l}\text { Double-sided } \\
\text { Prismatic notch }\end{array}$ & 1,176 & 3,404 & 6,567 & 7,338 & 3,529 \\
\hline $\begin{array}{l}\text { Double-sided } \\
\text { Elliptical notch } \\
\end{array}$ & 2,014 & 4,877 & 7,455 & 7,260 & 3,492 \\
\hline \multicolumn{6}{|c|}{$d=45 \mathrm{~mm}$} \\
\hline U-notch & 1,491 & 2,211 & 2,823 & 4,145 & 3,295 \\
\hline V-notch & 3,293 & 1,878 & 1,506 & 5,653 & 4,494 \\
\hline Prismatic notch & 1,532 & 3,285 & 2,420 & 4,443 & 3,532 \\
\hline Elliptical notch & 1,436 & 3,577 & 3,086 & 3,918 & 3,115 \\
\hline $\begin{array}{l}\text { Double-sided U- } \\
\text { notch }\end{array}$ & 1,762 & 4,675 & 2,653 & 2,973 & 2,363 \\
\hline $\begin{array}{l}\text { Double-sided V- } \\
\text { notch }\end{array}$ & 2,864 & 2,626 & 1,265 & 4,937 & 3,925 \\
\hline $\begin{array}{l}\text { Double-sided } \\
\text { Prismatic notch }\end{array}$ & 0,860 & 3,244 & 1,837 & 3,803 & 3,023 \\
\hline $\begin{array}{l}\text { Double-sided } \\
\text { Elliptical notch }\end{array}$ & 1,686 & 3,405 & 2,841 & 3,640 & 2,893 \\
\hline
\end{tabular}

Fig. 3 presents the stress concentration coefficients for all studied cases, as a function of the geometric ratio $\mathrm{d} / \mathrm{D}$.

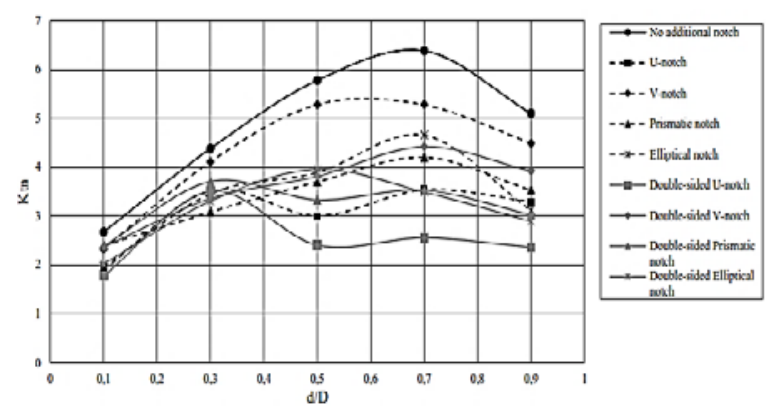

Fig. 3. Stress concentration coefficients for all studied cases, as a function of the geometric ratio d / D.

The obtained results show that the presence of additional notches significantly reduces the stresses in the endangered areas. The most significant influence in the present study is exerted by the double sided U-notch. With it, the stress concentration factor decreases by more than $30 \%$ compared to the results obtained without the presence of additional notches.

Table V presents the results for the maximum stresses and the stress concentration coefficient obtained in the simulation of the cylindrical stepped specimen, at different radius of fillet of the step.

TABLE V.

\begin{tabular}{|c|c|c|c|c|}
\hline \multicolumn{5}{|c|}{$\begin{array}{l}\text { Results of the simulation of a cylindrical specimen with } \\
\text { shoulder fillet. }\end{array}$} \\
\hline Parameter & Axial force & $\sigma$ nom & $\sigma \max$ & Ktn \\
\hline$r, \mathrm{~mm}$ & $P, N$ & $M P a$ & $M P a$ & - \\
\hline 2,7 & \multirow{5}{*}{100000} & \multirow{5}{*}{174,656} & 361,4 & 2,069 \\
\hline 4,05 & & & 323,22 & 1,851 \\
\hline 5,4 & & & 298,33 & 1,708 \\
\hline 6,75 & & & 276,58 & 1,584 \\
\hline 8,1 & & & 262,92 & 1,505 \\
\hline
\end{tabular}

In Fig. 4 shows the notch shapes used in the simulation of the stepped cylindrical specimen.

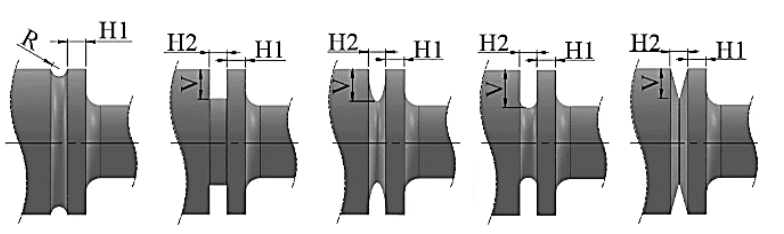

Fig. 4. Geometric parameters and shapes of the notches used in the simulation of the stepped specimen.

Table VI presents the values of the geometrical parameters of the notches, the maximum values of the stresses in the endangered areas, as well as the stress concentration coefficient obtained after the optimization with OptiSLang. 
TABLE VI.

\begin{tabular}{|c|c|c|c|c|c|}
\hline $\begin{array}{c}\text { Additional } \\
\text { notches }\end{array}$ & $\begin{array}{l}\text { H1, } \\
\text { mm }\end{array}$ & $\begin{array}{l}\text { H2, } \\
\text { mm }\end{array}$ & $\begin{array}{l}\text { V1, } \\
\text { mm }\end{array}$ & $\begin{array}{c}\sigma \text { max, } \\
\text { MPa }\end{array}$ & $\begin{array}{c}\text { Ktn } \\
-\end{array}$ \\
\hline \multicolumn{6}{|c|}{$r=2,7 \mathrm{~mm}$} \\
\hline U-notch & 7.166 & 3.242 & 10.471 & 310.743 & 1.779 \\
\hline V-notch & 8.667 & 1.425 & 5.366 & 355.476 & 2.035 \\
\hline $\begin{array}{l}\text { Prismatic } \\
\text { notch }\end{array}$ & 9.885 & 4.334 & 7.283 & 340.392 & 1.949 \\
\hline $\begin{array}{l}\text { Elliptical } \\
\text { notch }\end{array}$ & 8.197 & 2.271 & 6.028 & 344.039 & 1.970 \\
\hline $\begin{array}{l}\text { Semicircular } \\
\text { notch }\end{array}$ & .018 & \multicolumn{2}{|c|}{$\mathrm{R}=1.520 \mathrm{~mm}$} & 351.458 & 2.012 \\
\hline \multicolumn{6}{|c|}{$r=4,05 \mathrm{~mm}$} \\
\hline U-notch & 8.273 & 2.033 & 9.134 & 304.926 & 1.746 \\
\hline V-notc & 7.234 & 3.586 & 1.161 & 317.822 & 1.820 \\
\hline $\begin{array}{l}\text { Prismatic } \\
\text { notch }\end{array}$ & 7.803 & 3.696 & 4.451 & 318.712 & 1.825 \\
\hline $\begin{array}{l}\text { Elliptical } \\
\text { notch }\end{array}$ & 007 & 4.542 & 9.140 & 172 & 1.753 \\
\hline $\begin{array}{l}\text { Semicircular } \\
\text { notch }\end{array}$ & 9.939 & \multicolumn{2}{|c|}{$\mathrm{R}=9.987 \mathrm{~mm}$} & 03.824 & 1.740 \\
\hline \multicolumn{6}{|c|}{$r=5,4 \mathrm{~mm}$} \\
\hline U-notch & .522 & 4.278 & 10.155 & 277.760 & 1.590 \\
\hline V-not & 779 & 2.655 & 0.977 & 293.532 & 1.681 \\
\hline $\begin{array}{l}\text { Prismatic } \\
\text { notch }\end{array}$ & 5.863 & 4.897 & 6.061 & 291.457 & 1.669 \\
\hline $\begin{array}{l}\text { Elliptical } \\
\text { notch }\end{array}$ & 6.886 & 4.209 & 7.947 & 288.098 & 1.650 \\
\hline $\begin{array}{l}\text { Semicircular } \\
\text { notch }\end{array}$ & 7.434 & \multicolumn{2}{|c|}{$\mathrm{R}=9.999 \mathrm{~mm}$} & 777 & 1.619 \\
\hline \multicolumn{6}{|c|}{$r=6,75 \mathrm{~mm}$} \\
\hline U-notc & 666 & 3.565 & 9.207 & 267.454 & 1.531 \\
\hline V-not & 5.830 & 0.777 & 0.500 & 273.844 & 1.568 \\
\hline $\begin{array}{l}\text { Prismatic } \\
\text { notch }\end{array}$ & 4.521 & 1.652 & 5.893 & 274.309 & 1.571 \\
\hline $\begin{array}{l}\text { Elliptical } \\
\text { notch }\end{array}$ & 8.967 & 4.704 & 6.965 & 272.547 & 1.560 \\
\hline $\begin{array}{l}\text { Semicircular } \\
\text { notch }\end{array}$ & 2.853 & \multicolumn{2}{|c|}{$\mathrm{R}=9.908 \mathrm{~mm}$} & 265.375 & 1.519 \\
\hline \multicolumn{6}{|c|}{$r=8,1 \mathrm{~mm}$} \\
\hline U-notch & 6.165 & 4.562 & 9.367 & 254.801 & 1.459 \\
\hline V-notc & 350 & 1.151 & 5.123 & 260.696 & 1.493 \\
\hline $\begin{array}{l}\text { Prismatic } \\
\text { notch }\end{array}$ & 6.135 & 1.976 & 3.389 & 260.875 & 1.494 \\
\hline $\begin{array}{l}\text { Elliptical } \\
\text { notch }\end{array}$ & 1.144 & 1.709 & 5.418 & 261.017 & 1.494 \\
\hline $\begin{array}{l}\text { Semicircular } \\
\text { notch }\end{array}$ & 5.8 & \multicolumn{2}{|c|}{$\mathrm{R}=10 \mathrm{~mm}$} & 498 & .463 \\
\hline
\end{tabular}

In Fig. 5 the stress concentration coefficients are presented in a graphical form as a function of the geometric ratio $\mathrm{r} / \mathrm{d}$.

The analysis shows that the best results are achieved in the presence of an additional U-shaped notch. With it, the stress concentration coefficients decrease by more than $10 \%$.

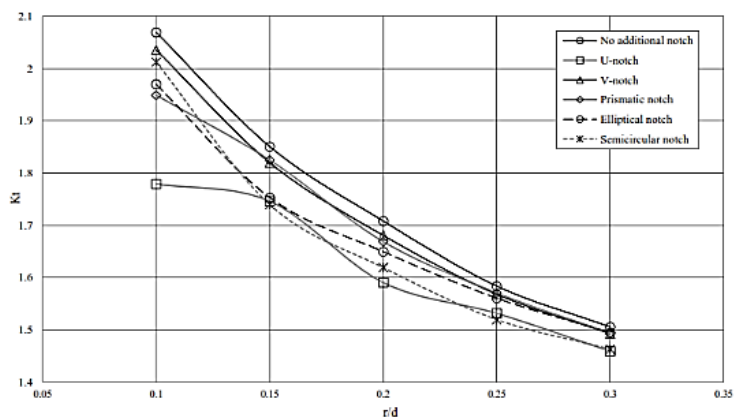

Fig. 5. Stress concentration coefficients for all studied cases, as a function of the geometric ratio $\mathrm{r} / \mathrm{d}$.

\section{CONCLUSIONS}

The aim of the present study is to determine the influence of the additional notches on the stress concentration in the examined specimens with the help of specialized software. The results of the performed simulations show that with a certain shape, geometric dimensions and location on the studied specimen, the stresses in the endangered areas can be significantly reduced.

The obtained results can be used as a starting point for forthcoming experimental studies.

\section{ACKNOWLEDGEMENTS}

The authors would like to thank the Research and Development Sector at the Technical University of Sofia for the financial support.

\section{REFERENCES}

[1] J. M González-Mendoza., S. Alcántara-Montes., J. Silva-Lomelí., C. Cruz-Alejo and A. Ocampo-Ramírez, "Size optimization of shoulder filleted shafts with relief grooves for improving their fatigue life”, IngenIería e InvestIgacIón vol. 37 №3, december 2017 (85-91),

http://dx.doi.org/10.15446/ing.investig.v37n3.57957

[2] Y Otsuka, H. Baron and Y. Mutoh, "Design Optimization of Stress Relief Grooves in Lever Guide of Pressure Vessel for Food Processing", Open Journal of Safety Science and Technology, 2012, 2, 1-7.

http://dx.doi.org/10.4236/ojsst.2012.21001

[3] F. Sonmez "Optimal shape design of shoulder fillets for flat and round bars under various loadings”, IMechE Vol. 223 Part C: J. Mechanical Engineering Science, 2009. https://doi.org/10.1243/09544062JMES1457

[4] V. Prasad, B Ram B, K. Krishna, T Reddy and S Kumar, "Stress Concentration Factors For Shouldered Shaft With Fillet And Taper Loaded In Tension", International Journal Of Scientific \& Technology Research, volume 9, issue 04, April 2020.

[5] C. Mattheck, M. Scherrer, K. Bethge and L. Tesari, "Shape Optimization: An Analytical Approach", WIT Transactions on the Built Environment, Volume 80, 2005.

[6] W. Pilkey, D. Pilkey and Z. Bi, "Peterson's Stress Concentration Factors, 4th Edition", ISBN: 978-1-119-53252-1, Wiley, January 2020. 